\title{
Cena
}

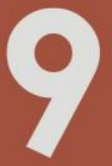

Dossiê Dança em Desdobramentos

PERIÓDICO DO PROGRAMA DE PÓS-GRADUAÇÃO EM ARTES CÊNICAS

INSTITUTO DE ARTES | DEPARTAMENTO DE ARTE DRAMÁTICA

UNIVERSIDADE FEDERAL DO RIO GRANDE DO SUL

\section{DESDOBRAMENTOS E INQUIETUDES DE UMA ARTISTA EM MOVIMENTO}

\section{Luiza Romani Ferreira Banov}

Bailarina, Coreógrafa, Pesquisadora, Bacharel (2006) e Licenciada em Dança UNICAMP. Mestranda no Programa de Pós-Graduação no Instituto de Artes da UNICAMP/ FAPESP, no qual desenvolve o trabalho cênico, em processo, "Aos que aqui estiveram".

\section{Sayonara Pereira}

Professora efetiva (RDIDP) na Escola de Comunicações e Artes - Departamento de Artes Cênicas, da Universidade de São Paulo. Doutora em Artes-Dança pela UNICAMP (2007). Pós-doutorado (2007-2009) junto ao Instituto de Artes da UNICAMP. 
RESUMO: O presente artigo busca realizar uma abordagem reflexiva sobre a artista Susanne Linke, a partir de sua concisa trajetória na dança moderna alemã e de suas obras Wandlung, Im Bade wannen, Flut e Frauenballett. As metodologias empregadas foram respectivamente: pesquisa-ação, pesquisa biblio e videográfica, e entrevistas dirigidas. Além disso, trazemos para o texto experiências da nossa participação em um estágio prático, dirigido por Linke, durante a remontagem da obra Frauenballett, junto à Companhia Folkwang Tanz Studio,de Essen, na Alemanha no mês de Janeiro de 2010.

PALAVRAS-CHAVE: Susanne Linke; Tanztheater; Dança.

ABSTRACT: The present article shows a reflective view about Susanne Linke trough her consistent trajectory in German Modern Dance and her pieces Wandlung, Im Bade wannen, Flut and Frauenballett. The methodology used for the study was: "research-action", research biblio and videográph study and informal interviews. Beyond that, we bring to the text our experience in a practical study, directed by Linke during the remaking of the piece Frauenballett with the cast of Folkwang Tanz Studio, Essen, Germany in the month of January, 2010.

KEYWORDS: Susanne Linke; Tanztheater; Dance.

\section{INTRODUÇÃO}

O presente artigo propõe uma abordagem reflexiva sobre a artista Susanne Linke a partir de sua concisa trajetória na dança moderna alemã. A pesquisa teve seu início no Festival de dança Mesa Verde ${ }^{1}$, onde foi possível conhecer Susanne Linke e também assistir as partes de sua obra ao vivo, tema este, que será discorrido ao longo do texto. Desta forma, algo especial e notório do evento, entre outras coisas, foi a compreensão concreta de que o artista da dança não possui idade para realizar sua arte. Para isso, é necessária muita devoção, disciplina e seriedade em relação ao trabalho realizado. A presença de Linke em cena e em momentos de maior descontração transmite claramente as características citadas logo acima.

Assim, nas próximas páginas faremos uma breve discussão sobre suas obras Wandlung (1978), Im Bade wannen (1980) e Flut (1981), trabalhos solos que fazem parte do repertório de apresentação de Linke junto a bailarinos convidados.

\footnotetext{
${ }^{1}$ Este festival aconteceu na cidade de Porto Alegre em Novembro de 2009.
} 
Além disso, trazemos para o texto experiências da nossa participação em um estágio prático, dirigido por Linke, durante a remontagem da obra Frauenballett (1981) junto à Companhia Folkwang Tanz Studio, em Essen, Alemanha no mês de Janeiro de 2010.

Para o desenvolvimento metodológico desta pesquisa, foi utilizada, além da pesquisa biblio e videográfica, a metodologia da pesquisa-ação e entrevista dirigida. Segundo Cruz Neto (1998), na observação participante reside um vasto campo de possibilidade a pesquisar que não se pode obter por meio de perguntas, mas se "(...) observados diretamente na própria realidade, transmitem o que há de mais importante e evasivo na vida real" (CRUZ NETO, 1998, p. 58).

Muito semelhante à pesquisa-ação, pode-se dizer que nem toda pesquisa participante é pesquisa-ação, porém, toda pesquisa-ação se faz participante. Para a eficácia desse tipo de pesquisa, é necessário utilizá-la apenas no nível microssocial, ou seja, em pequenos grupos. De natureza empírica, a pesquisa-ação "consiste em organizar a investigação em torno da concepção, do desenrolar e da avaliação de uma ação planejada" (THIOLLENTE, 2007, p. 18). Sendo esta ação não trivial, ela se encontra em um

contexto favorável quando os pesquisadores não querem limitar suas investigações aos aspectos acadêmicos e burocráticos da maioria das pesquisas convencionais. Querem pesquisas nas quais as pessoas implicadas tenham algo a "dizer" e "fazer" [...] os pesquisadores pretendem desempenhar um papel ativo na própria realidade dos fatos observados (THIOLLENTE, 2007, 17).

\section{PASSOS E MEMÓRIA}

Susanne Linke teve sua infância marcada pela necessidade de comunicar-se. Quando pequena foi cunhada pela percepção visual do mundo, visto que não conseguia falar e, consequentemente, entender as pessoas. Ela era simplesmente incapaz de entender ou repetir palavras e não havia justificativa para isso. 
$\mathrm{Na}$ época, havia uma lei alemã que determinava que as crianças de seis anos que não pudessem falar deveriam ser encaminhadas para uma escola de surdos e mudos, entretanto, a mãe de Linke não concordava com isso e foi buscar resposta para a deficiência da filha. Desta maneira, na cidade de Hamburgo, Linke foi submetida a um exame psiquiátrico, que consistiu primeiro em uma internação de uma semana para observação.

O segundo exame realizado teve líquido cefalorraquidiano colhido de seu cérebro. Para este procedimento, realizado ainda quando pequena, permaneceu cerca de quatorze dias em uma clínica. Estas recordações de infância serviram, posteriormente, como a base de inspiração para a construção da peça Schritte Verfolgen (Passos Perseguidos), de 1985. Pereira (2007) relata sobre este solo que:

a protagonista leva a quem o assiste por estações do seu desenvolvimento: o desespero de não poder falar... a experiência de ter uma linguagem própria para se comunicar com o mundo; conhecimento intensivo com o corpo através da dança; a descoberta da beleza que acontece com 0 amadurecimento de uma coreografia, e depois com o seu amadurecimento pessoal como artista, até chegar à transcendência como criadora (PEREIRA, 2007, p. 71). ${ }^{2}$

Após a descoberta de que tudo não passava de uma meningite não tratada e que esta sua dificuldade em pronunciar e entender o significado dos sons não passava de algumas sequelas em seu cérebro, Linke foi internada em um local para tratamento da fala, onde aos poucos aprendeu a falar em um processo muito lento e preciso de aprendizado. Segundo a artista, sentia o som das letras através da pele e ia tentando repetir os fonemas.

Ao recordar-se da infância, Linke lembra que já dançava quando criança, ao som de um tambor que um menino que morava no mesmo local de seu tratamento, tocava. Além disto, enquanto sozinha, se movimentava ao som do ritmo que buscava encontrar em sua própria voz.

Foi, entretanto, entre dezesseis e dezessete anos que soube que uma artista solista viria a Frankfurt realizar um trabalho para o teatro local, curiosa

\footnotetext{
${ }^{2}$ Atualmente o solo se encontra em turnê com nova versão. Nela, a artista divide o palco com outras três artistas mais jovens, sendo cada uma delas responsável por uma dessas fases.
} 
foi assistir para ver o que era. A artista era Dore Hoyer ${ }^{3}$ e este encontro consolidou a certeza de Susanne Linke em ter encontrado o que desejaria fazer para resto de sua vida. Todavia, devido a sua idade, acreditava que já era tarde para realizar o sonho de ser bailarina, mas encorajada por Dore Hoyer, decidiu partir diretamente a Berlim onde foi estudar na escola de Mary Wigman, na qual permaneceu por um período de três anos.

Entrou na escola aos vinte anos e, deste momento, acredita possuir fortes influências até os dias atuais. Segundo Linke, Wigman não tinha interesse em fornecer determinada técnica, o que era muito importante, visto que se fazia necessário que cada intérprete descobrisse os movimentos com o próprio corpo. "Na sua escola aprendemos muito como utilizar o tronco e braços, mas acima de tudo, como usar a alma para mover o corpo, independente do que se movimenta. Com Wigman tínhamos que encontrar uma unidade absoluta", afirma Linke (1994).

Após o término da escola de Mary Wigman, fechada em 1967, sendo a turma de Susanne Linke a última a se formar, a jovem artista percebia que deveria continuar seus estudos para adquirir mais técnica. Foi quando ouviu falar da escola de Kurt Jooss, a Folkwang Hochschule de Essen, e se direcionou para lá.

Logo após um ano de sua chegada, em 1968, Jooss se aposentou deixando a Susanne Linke seu segundo mestre, Hans Züllig. É Züllig, segundo a artista, que definiu sua relação corporal com o movimento e aperfeiçoou seu trabalho e agilidade com as pernas. Linke acredita ser imprescindível ao bailarino este trabalho que desenvolve a precisão: "no palco não se pode estremecer", diz ela.

Durante seu período na Folkwang, Linke pode ter contato com outros artistas como Jean Cébron e Pina Bausch, inclusive Bausch a dirigiu em seu período de trabalho no Folkwang Tanz Studio. Em 1975 Linke assume, junto

3 Pereira (2007) afirma ainda que o solos de Hoyer, Affectos Humanos, de 1962, são remontados até os dias de hoje por bailarinos contemporâneos. Susanne Linke afirma ter sido muito influenciada por esta artista, inclusive, remontou um conjunto de solos de Hoyer, denominado Affectos Humanos, pela primeira vez em 1987. "Dolor" realizando posteriormente, em 1988, é um solo em homenagem a Dore Hoyer realizado por Linke e incluído por ela no ciclo de solos Affectos Humanos. 
com Reinhild Hoffmann, a direção do Folkwang Tanz Studio, onde permaneceu por nove anos. Nesse período coreografou nove obras para a companhia, entre elas: Danse funebre (1975), Frauenballett (1981), Die Nachste Bitte (1978), Wir konnen nicht alle nur Schwane sein (1982). Concomitantemente, apresentou espetáculos solos, entre eles: Wandlung (1978), Im Bade wannen (1980), Flut (1978), Es schwant ..., (1982).

Entre os anos de 1985 e 1994, Linke sai em turnê mundial com seus solos, e entre 1994 e 1996 assume a direção do Bremen Tanztheater - na Ópera de Bremen, junto com seu companheiro Urs Dietrich, o qual permanece até hoje como diretor do grupo. Segundo o critico Schmidt (1997, p. 10), "Com Susanne Linke e um jovem co-diretor da Suiça, Urs Dietrich na direção, o Tanztheater Bremen sentiu novamente seus belos dias, e ficou à frente no ranque dos ensambles lideres da Alemanha" 4 .

Atualmente, Linke trabalha novamente como artista independente fazendo apresentações pelo mundo, remontando seus trabalhos com artistas mais jovens e também continua a coreografar. Além disso, encontra- se em processo de solidificação de um método próprio de treinamento corporal. Este método vem sendo desenvolvido pela coreógrafa desde os anos 80 , período que assinala seu primeiro workshop em Lima.

Sempre muito preocupada com a preparação física do artista, Linke vem trabalhando uma nova forma de se mover e de treinar tanto expressividade como técnica corporal. Na busca por movimentos que a fizessem "sentir o vento" em seu rosto conseguiu mesclar exercícios oriundos da escola de Wigman com o trabalho mais técnico desenvolvido por Züllig.

Uma das premissas do trabalho corporal de Linke é transferir a barra utilizada nas aulas de balé clássico e dança moderna para o eixo central da coluna, com exercícios desenvolvidos no centro, sempre com movimentos extremamente ritmados de pernas em um tempo, braços relaxados em outro, sem esquecer 0 volume dos movimentos. Existe o desejo e a possibilidade desta artista, ainda, de sistematizar seu método de treinamento. Segundo Linke, são exercícios que fazem parte de seu treinamento diário.

\footnotetext{
${ }^{4}$ Tradução: Luiza Banov.
} 
Neste sentido, revela-se o encontro com o paralelo: dança - vida, este que permeia nossa sociedade, horas mais presente, horas menos; mas que certamente serve como eixo para o caminho de todos os artistas da dança que ousam fazer dela sua fonte de alimento para viver.

\section{SOLOS}

"Ao longo dos primeiros quarenta anos do século XX, portanto, o solo se torna uma constante nas criações de dança... As novas solistas... transformam a representação de um papel em expressão de uma pessoa; seus corpos não são uma máscara, pelo contrário, como se dirá na Alemanha, vestem a alma como uma luva" (ROPA, 2009, p. 66).

No final do século XIX, início do século XX, a dança foi marcada por intensas transformações através da tomada do culto ao corpo. Foi o momento em que os artistas buscaram uma dança mais autoral e reflexiva, na qual o intérprete pudesse se expressar e discutir os problemas da sociedade moderna.

Assim, desde então, muitos artistas passaram a criar trabalhos solos em dança, como foi o caso de Isadora Duncan.

Para Ropa (2009):
a nova dança para o novo século é individual e individualista, realização solitária de personalidades singulares e únicas, que escolhem e elaboram novas modalidades expressivas e performáticas e se colocam como modelos exemplares não só no interior da própria disciplina artística, bem como na sociedade em transformação... Daquele momento em diante, a dança solo se torna e permanece uma forma característica e constante por todo o século - e ainda o é no início do século XXI - como uma necessidade do artista moderno seja de pesquisa introspectiva como de uma maneira pessoal de refletir o mundo (ROPA, 2009, p. 62).

$\mathrm{Na}$ Alemanha Mary Wigman e Dore Hoyer podem ser vistas como pioneiras da dança solo com trabalhos que são remontados até os dias atuais, como é o caso das obras A bruxa (1926) e Affectos Humanos (1962) de ambas as artistas, respectivamente, que, além disto, muito influenciaram protagonistas da geração que seguiu.

As características dos solos realizados por mulheres se transformam 
entre os anos sessenta. Anteriormente, as representações eram elaboradas a partir de um viés mais espiritual, os desejos femininos eram impressos por uma necessidade de relacionar-se com a natureza, e com os desejos profundos da alma. Posteriormente, entretanto, o desejo de libertação da alma se revelou de uma nova maneira nas obras de artistas como Linke e Hoffmann, através da necessidade de busca por um feminismo, no qual as intérpretes chegam a "lutar" em cena com objetos que as prendam ao papel de dona de casa.

A carreira de Linke se edificou principalmente a partir de seu trabalho como bailarina solo. Para ela, esta trajetória acabou ocorrendo de forma natural. Segundo Pereira (2007):

um dos tópicos fascinantes na obra de Susanne Linke é o andrógeno, como a parte feminina e a parte masculina trabalham no corpo. Como estas duas partes brigam o tempo inteiro, uma com a outra, mas, também como elas podem encontrar um equilíbrio. É comum encontrar nas coreografias de Susanne Linke homens e mulheres trajando a mesma roupa, o que os tornam mais anônimos (PEREIRA, 2007, p. 70).

Susanne Linke, que possui a emancipação feminina como um dos temas que acompanham suas obras revela a relação homem/mulher, ao se tratar de seus intérpretes de maneira bastante peculiar.

É fato que em muitas de suas obras, inclusive em seus solos, a coreógrafa experimentou executá-las com bailarinos homens e mulheres, como acontece atualmente no solo Flut. Este é atualmente encenado pelo bailarino Urs Dietrich, que é também seu companheiro de vida a mais de 20 anos. A opção de Dietrich encenar esta obra se deve tanto à dificuldade técnica da mesma, como também pela experiência de uma energia masculina em um solo feito e realizado por uma mulher.

Em entrevista, quando questionada sobre a diferença entre bailarinos homens e mulheres, Linke disse: "As mulheres são melhores para mostrar emoção, mais abertas para viver o momento. Os homens precisam de uma estrutura mais rígida" (LINKE, 2008).

Ropa (2009) revela muitas características ideológicas sobre a necessidade do artista em estar só no palco, revela que o solo na dança: 
apresenta a dançarina sozinha com seu corpo e suas emoções reveladas na cena, são uma provocação viva não somente à instituição coral, uniformizada e tecnicista do balé, mas à completa concepção da mulher e de seu papel na sociedade (ROPA, 2009, p. 63).

Atualmente tanto nas programações de teatros mais convencionais, como nas de teatros mais alternativos é possível apreciar a diferentes espetáculos - solo de dança contemporânea. Este fato revela também o modo em que se encontra o estado da dança, no contexto sociocultural. Pela lacuna de incentivos concebidos à arte, de maneira geral, o solo além de ser uma possibilidade de sobrevivência, para o autor, é também a busca de uma caligrafia pessoal, em um mundo paradoxalmente globalizado, e individualista.

Para Ropa, (2009, p. 62) este fator se revela também "como uma necessidade do artista moderno seja de pesquisa introspectiva como de uma maneira pessoal de refletir o mundo. Todavia, sua contribuição à reflexão e à crítica social assume nuances diversas de acordo com os diferentes contextos históricos". Assim esta autora revela ainda que no século XXI "...o solo de dança continua a produzir, sem clamor, mas com insistência tenaz, através da presença incongruente e do contágio empático de seus corpos vivos e falantes no movimento, sua crítica silenciosa, direta ou indireta, à sociedade que o circunda e o gera" (ROPA, 2009, p. 62).

\section{FLUT, IM BADE WANNEN E WANDLUNG; UMA BREVE REFLEXÃO...}

Dentre o vasto repertório coreográfico de Susanne Linke, foi nos oportunizado, assisti-la pela primeira vez ao vivo, no Festival de Dança Mesa Verde, realizado em novembro de 2009, na cidade de Porto Alegre/RS. A possibilidade de vê-la no palco, além das telas de uma televisão, das páginas de um livro ou até mesmo de um web-site, foi extremamente significativa, pois concretizou sua imagem, sua dança, sua arte. Falaremos a seguir um pouco a respeito das obras com as quais Linke nos presenteou na noite em que a assistimos no Festival Mesa Verde.

$\mathrm{Na}$ ocasião, sua noite de solos, antigamente interpretada inteiramente por ela, contou com dois ilustres convidados: Urs Dietrich e Mareike Franz para interpretar solos que se tornam mais complexos para Linke, executar em sua 
maturidade. Sobre essa noite de solos realizada em Porto Alegre, Pereira, 2009 afirmou: "Ao seu público, Linke proporciona a possibilidade de visualizar uma transparência em suas criações. Para que isso se concretize, em suas obras ela concilia a técnica de dança aos planos físico e espiritual" (PEREIRA, 2009).

Nas obras de Linke pudemos compreender o silêncio como parte integrante e importante do significado. O silêncio está presente de diversas formas, é produzido, e não sobreposto ao dizer.

Em Flut (Maré), obra concebida em 1981, com estréia no Theater Rheydt, Monchegladbach - Alemanha, a ausência de cenário e apenas um tecido azul de vinte metros como objeto cênico permite o espaço para o vazio visual no palco. Apenas um intérprete percorre toda a caixa preta que se encontra em silêncio, à espera de seu dizer. A peça trata sobre as angústias humanas, sobre pensamentos, "barulhos" que estão em nossa mente, com os quais não sabemos lidar. A dificuldade do intérprete de lidar com um imenso tecido, que é transportando pelo palco, nos sugerem diferentes associações, novas imagens, além disso, nos indicam a percorrer outros ambientes que não o palco, talvez, o mar?

A iluminação é simples e a música transita entre o ensaio de uma orquestra, a ausência do som, o som das notas em sintonia, e também as correções do maestro em determinados momentos da música que está sendo ensaiada; estas correções geram repetições, assim como acontecem em ensaios de dança, de música ou mesmo da vida.

O tecido, que permanece no palco durante toda a cena, some subitamente pela coxia, deixando o intérprete só, no centro do palco, sem saber para onde ir. Afinal, o que pensamos é real? Nossos pensamentos estão realmente em nossa mente, o barulho, o silêncio, a ausência, o que é real? Tudo não passa de uma ilusão?

Pudemos estabelecer um paralelo entre estas questões e o livro de Clément Rosset, "O real e seu duplo" (2008), em que o autor discorre sobre a "realidade ilusória" da vida, na qual vivemos sempre em um duplo de algo já existente: 
O real só começa no segundo lance, que é a verdade da vida humana, marcada com a rubrica do duplo: quanto ao primeiro lance, que não duplica nada, é precisamente um lance inútil. Em suma, para ser real, segundo a definição da realidade neste mundo, duplo de um inacessível real, é preciso copiar alguma coisa; ora, este nunca é o caso do primeiro lance, que não copia nada: só resta então deixá-los aos deuses, os únicos dignos de viverem sob o signo de único, os únicos que são capazes de conhecer a alegria do primeiro (ROSSET, 2008, p. $65)$.

Seria, portanto, a arte o duplo de muitos duplos? De duplos que são a vida? De certa forma, aquela realidade que se apresenta na obra Flut, em que o intérprete se depara o tempo inteiro com um tecido que some ao final da peça deixando sem saber ao certo o que ele estava fazendo ali, nos leva um pouco para esta reflexão do inconsciente, onde o silêncio da cena é, na verdade, o barulho da mente.

No Festival de Dança Mesa Verde, Flut foi "reescrita" por Dietrich e sobre sua atuação Pereira (2009) afirma: "A maturidade e a extensão expressiva da movimentação de Dietrich tomam conta da cena e, mesmo que tenhamos na lembrança esboços da versão dançada por Linke, a atuação dele não deixa por menos: muito coesa, revela um corpo profundamente identificado com o que está executando" (PEREIRA, 2009).

Im Bade wannen (Na banheira), que teve sua estréia em 1980, no teatro da Folkwang Hochschule - Essen, e que já havia sido encenada anteriormente no Brasil no ano de 1986, é uma obra que permite a vazão do espaço cênico para apenas um corpo. Criada a partir do desejo de utilizar em cena um objeto tão comum, de uso diário e íntimo como, por exemplo, uma banheira e um vaso sanitário. Na obra estes objetos foram re-significados até chegar ao universo de uma mulher e seus pensamentos ao realizar tarefas diárias em sua solidão.

A artista inicia o espetáculo sentada de costas para o público em um vaso sanitário e então se direciona à banheira que se encontra ao seu lado direito. Através de movimentos que remetem à limpeza inicia sua dança. Silva (2007) descreve esta obra:

[...] dos seus mais belos solos, intitulado Im Bade wannen (1984), faz uma banheira transformar-se em seu partner. Com música de Erik Satie, Linke dança dentro, em volta e com a banheira, como um cão preso numa corrente em volta de uma 
árvore, desesperançosa e, ao mesmo tempo, profundamente apaixona por essa escravidão (SILVA, 2007, p. 11).

Sobre a solidão e angústia feminina, a obra vai além deste espaço externo íntimo e parte para uma intimidade mais densa do ser humano.

Com o florescer do feminismo contemporâneo, muitas dançarinas descobrem e revelam com lúcida ironia a alienação e as neuroses da mulher na sociedade de consumo. Lucinda Childs, Susanne Linke, Reinhild Hoffmann, por exemplo, lutam em cena contra objetos de fetiche que as prendem ao papel de donas-de-casa e consumidoras e parecem inibir nelas qualquer uso não neurotizado do próprio corpo (ROPA, 2009, p. 65).

Esta banheira ganha sentidos diversos, chegando a ser um "partner" para a intérprete em cena, ora sendo protagonista, ora coadjuvante. "Além de atingir um instante extremamente poético, a personagem também mostra uma possibilidade de transcendência dentro de seu dia-a-dia. Ao realismo captado com um olhar bem direcionado na dificuldade, há por outro lado a capacidade de superar essa situação" (PEREIRA, 2009).

A música de Eric Satie transita entre a pausa e a continuidade em momentos que se sobrepõem ao movimento e em momentos em que se justapõem. Ou seja, há momentos em que o movimento dialoga diretamente com a música; em outros se apresenta como pano de fundo; ou ainda, a música se silencia para que apenas o gesto corporal venha a dizer. Esta relação subjetiva com a música encontra respaldo nos dizeres de Lomakine (1999):
A correspondência "dança para música" sinalizou uma mudança radical na história da dança avant garde do século XX. A maior mudança de valores dos coreógrafos da nova dança dos anos 80 , em relação a seus antecessores dos anos 60 e 70, foi a utilização da música, que é sem dúvida um dos meios-chave para se buscar expressão na dança, uma vez que esta tem o poder de criar todo um humor. Até os anos 80 a tendência dos pós-modernos foi separar a dança da música, pois segundo eles a dança legitima como uma realidade autônoma (LOMAKINE, 1999, p. 74).

Susanne Linke revelou, durante conversa informal, na cidade de Essen Werden/ Alemanha, em janeiro de 2010, que a música nunca deve ser seguida pelos passos do bailarino, contudo, também não deve ser ignorada. Este equilíbrio permite o encontro com a poesia. 
Para refletirmos sobre os momentos em que ocorrem pausas de movimento na cena de Linke encontramos auxílio nas palavras da bailarina Regina Advento, que fala a respeito do tempo, movimento e música na dança teatral: "Pina Bausch sempre fala que um movimento é bom; se ele sem música é bom, se tem um ritmo, existe a música interior de cada movimento. Procuro sempre trabalhar a sonoridade do movimento" 5.

A questão rítmica na Dança Teatral é intensa. Talvez seja possível localizar a sua origem devido às influências de Jaques - Dalcroze com a ginástica rítmica, além das influências na dança clássica, que é inteira realizada nos compassos musicais. Podemos ainda arriscar falar que a precisão do gesto no "tempo-ritmo" se influencia de alguma maneira pela própria cultura germânica.

Pavis (2003) diz sobre o ritmo que "A determinação do tempo-ritmo é a tarefa do ator que imprime sua marca e o seu tempo-ritmo interno à enunciação de seu texto e de seu papel" (PAVIS 2003, p. 147). Neste sentido, observamos que a busca da precisão e certeza do movimento executado faz com que o próprio intérprete crie seu ritmo, o tempo no espaço em que vive sua existência, e desta maneira o coreógrafo pode compor trechos musicais nas diversas maneiras em que desejar.

Através de outro olhar, encontramos em Orlandi (2007) que na:

relação entre a palavra e o silêncio: a palavra imprime-se no contínuo significante do silêncio e ela o marca, o segmenta e o distingue em sentidos discretos, constituindo um tempo (tempus) no movimento contínuo (aevnum) dos sentidos do silêncio. Podemos enfim dizer que há um ritmo no significar que compõe o movimento entre silêncio e linguagem (ORLANDI, 2007, p. 25).

O tempo se mostra como uma das peças-chave para a construção cênica, algo muito necessário ao intérprete, já que nasce da relação do sujeito com o mundo. Por outro lado, a obra de Linke Wandlung, que teve sua estréia em 1978, no Theater Heidelberg, é uma obra ancestral. Dedicada a Mary Wigman, é um fluxo contínuo em que se questiona a passagem da vida e da

\footnotetext{
${ }^{5} \mathrm{Em}$ entrevista (transcrita posteriormente por Luiza Banov) realizada em Essen/Alemanha, por Sayonara Pereira, em janeiro de 2009, como parte do material para seu Pós-Doutorado- "O que descreve o Gesto “/ UNICAMP-FAPESP (2007-2009). No prelo.
} 
morte. Nela, a intérprete percorre em movimentos contínuos os níveis e as dimensões do palco, como que flutuando em uma viagem para um lugar desconhecido. Diferentemente de Flut e Im Baden wannen não possui objeto cênico, mas igualmente se "reduz" à bailarina e ao espaço do palco: não há nenhum cenário. Figurino simples e nenhum cenário ou objeto cênico, luz amena, a artista desenha entre o vazio do palco trazendo a dramaticidade à cena. Afirma Pereira (2009) a respeito:

Atual em sua concepção, esse solo é muito significativo
tecnicamente porque a princípio ele se apresenta como um
despertar, um espreguiçar de movimentos muito simples.
Porém, à medida que se desenvolve, apresenta uma caligrafia
muito própria, baseada em técnica precisa e apurada
(PEREIRA, 2009).

Atualmente não é mais Linke que a interpreta devido ao esforço necessário e ao seu alto nível técnico. Este fator é uma das razões pelas quais suas obras têm sido aos poucos e minuciosamente ensinadas a artistas jovens, que passam a reescrever seus papéis na cena, sempre com a apurada direção de ensaios da própria Linke.

Em conversa informal com a artista, ela revelou que Wandlung não foi bem recebida pelo seu mestre Hans Züllig, quando criada. Segundo Linke, Züllig acreditava que esta obra não deveria ser feita. Porém, Linke sempre acreditou que devemos fazer até o final o que acreditamos, e que algo só pode ser efetivo se tivermos com nossa alma completamente envolvida nos objetivos propostos.

Ao assistir os três trabalhos relatados acima, pudemos encontrar elementos em comum. Quase sempre um elemento cênico desaparece, ou melhor, silencia para que outro possa dizer. É como se cada um desses elementos fosse uma voz e, então, em algum momento uma voz se cala para que outras possam ser ouvidas. O silêncio acontece de forma a compor a cena, o "não dizer" ao mesmo tempo se revela aliado do discurso cênico visto que direciona a atenção do espectador, seja na luz, no corpo, na música ou na ação. Além disso, os intérpretes não possuem voz apenas para um personagem, mas representam pessoas, sentimentos, imagens. Sobre isto Pavis, 2003 expõe: 
$\mathrm{Na}$ prática teatral contemporânea, o ator não remete mais sempre a uma pessoa verdadeira, a um indivíduo formando um todo, a uma série de emoções. Não significa mais por simples transposição e imitação; constrói suas significações a partir de elementos isolados que toma emprestado de parte do seu corpo (neutralizando todo o resto) (PAVIS, 2003, p. 55).

Outro elemento em comum observado nas peças de Linke foi a iluminação, que, de certa forma, é aliada da cena. Por se tratarem de solos, a luz esteve sempre centrada, focando o intérprete e sua ação. Além disso, bastante simples e na maior parte dos momentos quase que natural, sem muitos efeitos. Participa, também, na composição plástica e, assim como a música, transita num ir e vir, na ausência e na presença, compondo as ações e direcionando o olhar do espectador. De acordo com Pavis (2003), "A iluminação ocupa um lugar-chave na representação, já que ela a faz existir visualmente, além de relacionar e colorir os elementos visuais (espaço, cenografia, figurino, ator, maquiagem), conferindo a eles uma certa atmosfera" (PAVIS, 2003, p. 179).

Para o artista e pesquisador Flores (1996): "Susanne Linke se utiliza dos recursos cênicos como a cenografia e o vestuário em situações em que os significados se recodificam para gerar novos significantes" (FLORES, 1996, p. $22)^{6}$.

\section{FRAUENBALLETT, O BALÉ DAS MULHERES}

Foi em meados dos anos 70, em uma viagem à Índia com uma amiga, que Susanne Linke obteve as primeiras inspirações para a criação de Frauenballett. Segundo a coreógrafa, estava viajando de trem, lotado de passageiros, e durante a viagem observou que os homens encontravam-se todos sentados, enquanto que as mulheres viajavam em pé. Neste momento, deu-se conta da diferença imposta entre homens e mulheres, na qual os homens se colocam em posição superior e possuem mais reconhecimento em seus trabalhos. As mulheres trabalham muito, ganham pouco, e ainda são tratadas como inferiores.

\footnotetext{
${ }^{6}$ Tradução de Luciana Coutinho.
} 
$\mathrm{Na}$ visão da coreógrafa, a situação machista em que se encontrava aquela sociedade precisava de mudanças. Surpresa e decepcionada com a situação em que se deparava, Linke trouxe voz a esta temática em sua obra. Frauenballett vem tanto como uma postura feminista a isso, quanto também em forma de crítica.

Com trilha sonora de compositores renascentistas e com a obra musical de Krzysztof Penderecki, a coreografia inicia-se com o caminhar das mulheres que seguem para principiarem seu dia de trabalho. Existe uma célula de movimento que se torna um "late-motive" e se repete inúmeras vezes com algumas transformações. Na primeira cena, nove bailarinos se alternam em um cânone incansável que cruza o palco horizontalmente. Esse trajeto é feito ora com pliê, ora com acento no quadril, ora com ambos. A contagem também se transforma com a caminhada.

Os bailarinos manipulam tecidos que desenham o caminho pelo qual eles passam. Estes tecidos, coloridos, remetem às lindas vestimentas das mulheres indianas. Além de afirmarem uma postura feminista, representam a força e seu significado se transforma à medida que a obra se desenvolve. Suas cores são variadas entre tons de vermelho, amarelo, roxo, vinho e variações de rosa.

Para a versão atual ${ }^{8}$, Susanne Linke afirmou ter realizado pequenas alterações em relação à versão original, afinal, a última remontagem havia sido realizada dez anos antes. Os trechos coreográficos permaneceram o mais fiel possível, contudo, existem dois personagens da peça que antes representavam dois homens velhos. Na versão de 2010, Linke optou por "atualizá-los", transformando-os em homens de negócios, "mafiosos", e adicionou ainda um novo personagem que seria como um "capanga" destes possíveis bandidos.

\footnotetext{
7 "Plié: Dobrado. Refere-se a uma flexão do joelho ou dos joelhos. São dois os pliés principais: o grand plié e o demi-plié. No primeiro caso, a (o) bailarina (o) dobra pelos joelhos até que as coxas fiquem na horizontal. No segundo, fica no meio do caminho; daí demi-plié - meio plié. $\mathrm{O}$ plié é fundamental, básico, para a maioria dos passos executados pela (o) bailarina (o). Por isso, é um dos exercícios fundamentais feitos na barra e no centro de prática, tornando as juntas, os músculos e os tendões mais flexíveis e elásticos, ao mesmo tempo em que ajuda a controlar o equilíbrio" (PAVLOVA, 2000, 171).

${ }^{8}$ Luiza Banov teve a oportunidade de estagiar por um período na remontagem dessa peça, com o elenco do Folkwang Tanz Studio. A remontagem levou cerca de um mês e meio, entre janeiro e fevereiro de 2010, com estréia no dia 27 de fevereiro de 2010.
} 
Durante a peça, esses homens citam trechos do capítulo nove, intitulado Taxa de Mais Valia, da obra O Capital (1867), de Karl Marx, e se comunicam entre si através da língua de sinais; simulam uma situação onde o "capanga" é contratado por ambos os "mafiosos", cada um tencionando matar o outro; não existe fim para esta situação, que gera um suspense durante toda a peça.

Esta obra já foi encenada em diversos países, como Perú, Costa Rica, Brasil e Indonésia. No Brasil, inclusive, foi remontada pelo Grupo Corpo, de Belo Horizonte. Esta remontagem teve sua estréia no dia 15 de setembro de 1988, no Grande Teatro do Palácio das Artes, em Belo Horizonte, com coreografia, figurino e iluminação de Susanne Linke.

\begin{abstract}
Através da nomenclatura musical, Linke intensifica a expressão do corpo em um plano onde o movimento se hierarquiza em ações principais como o verbo na oração e sua localização posterior, dando ao afeto percussão para incrementar na medida em que declina ou repete o êxtase da dança: Entendase esse declínio como uma variação sobre o mesmo gesto, em um corpo sem origem ou morte, uma linha que não aceita fraturas, uma dança sem estações - onde, ainda na mais precisa detenção, o corpo suspenso dança - e, com ele, a dimensão criadora esvaziará os conceitos onde esse corpo em ressonância com o mundo do criador produzirá seus ruídos, pois tudo no drama é propósito; propósito que não é dado a compreender-se já que o universo da arte continua se centrando no homem e para o homem e, enquanto isso acontece, seu princípio será sempre 0 da arte dramática (FLORES, 1996, p. 22) ${ }^{9}$.
\end{abstract}

Durante os ensaios realizados para a remontagem da obra em 2010 com o Folkwang Tanz Studio, Linke estava muito absorvida em transmitir, além da forma de cada sequência de movimento, também sua intenção. "É preciso ter coragem para ser devagar", disse ela em um momento do ensaio em que não há música e os bailarinos devem iniciar a movimentação lentamente.

Provavelmente, nunca será possível encontrar palavras que descrevam o verdadeiro significado de conhecer e compartilhar momentos com esta incrível artista. Todo olhar sincero, palavra concedida, experiência dividida possuem sua função certeira, de estímulo e afeição aos jovens artistas que por motivos diversos das suas vidas oportunamente se cruzaram com a dela. $A$ força e intensidade dos movimentos que, ao mesmo tempo, possuíam algo de

\footnotetext{
${ }^{9}$ Tradução: Luciana Coutinho.
} 
etéreo e sublime; a exatidão e certeza encontrada em cada ação desempenhada são características que foram notórias ao longo da pesquisa.

\section{CONCLUSÕES}

Conhecer um pouco da obra e vida da artista Susanne Linke permite um vôo, uma calma, um aconchego para o "fazer" da dança atualmente. Sua força, garra, e intensa dedicação em seu trabalho, na dança, são inconfundíveis e insaciáveis, a ponto de estendê-la a sua vida.

Possuir um corpo afinado é algo que se faz vigente em sua história e cotidiano na dança, uma vez que até os dias de hoje esta coreógrafa se alimenta das aulas de dança como fonte de afinação de seu próprio corpo. $\mathrm{O}$ corpo é algo que se faz necessário para estabelecer um dialogo com os intérpretes, amplia as questões sensoriais que, dimensionando a relação direta com sua dança e vida, uma vez que, para Linke, ambas não se distinguem entre si.

Ao definir crucialmente esta relação, Linke consolida seu credo de que existe muito além de técnica e da forma para uma obra ser verdadeira e tocar o público.

Assim, chamamos atenção para sua ênfase sobre o ser - humano, suas experiências e relação com o mundo como sendo principal característica envolvendo o intérprete do Tanztheater.

Estar presente na cena sendo antes de tudo humano com os sentimentos e características inerentes a esta espécie é um dos preceitos que se pôde compreender como principal para o interprete cênico; este fato foi encontrado ao longo do trabalho e na pesquisa da artista Susanne Linke, assim como em tantos outros artistas que se viram imersos pela necessidade de expressar através desta arte.

\section{REFERÊNCIAS BIBLIOGRÁFICAS}

CRUZ NETO, Otavio. Pesquisa Social - teoria - método e criatividade. Rio de Janeiro: Vozes, 1998. 
FLORES, P. Leyson. Hacía uma dramaturgia Del movimiento. Anályses e reflexión sobre la dramaturgia em el discurso coreográfico en la danza contemporánea. Caracas: Collecion Canícula. 2000.

LOMAKINE, Luciana. (Re) descobrindo a dança em tempos pós-modernos. 1999. 206p. Dissertação (Mestrado em Artes). Instituto de Artes, Universidade Estadual de Campinas, Campinas, 1999.

ORLANDI, Eni Pulcinelli. As formas do silêncio. No movimento dos sentidos. Campinas: Editora da UNICAMP, 2007.

PAVIS, Patrice. Análise dos Espetáculos. Trad. Sérgio Sálvia Coelho. São Paulo: Perspectiva, 2003.

PEREIRA, Sayonara. Rastros do Tanztheater no processo criativo de ESBOÇO: espetáculo cênico com os alunos do Instituto de Artes da UNICAMP. 2007. 182p. Tese. (Doutorado em Artes). Instituto de Artes, Universidade Estadual de Campinas, Campinas, 2007.

ROPA, Eugenia C. O solo de dança no século XX: entre proposta ideológica e estratégia de sobrevivência. In: URDIMENTO. Revista de Estudos das Artes Cênicas. Santa Catarina: CEART/UDESC, 2009, V. 1, no. 12, pp. 61-72.

ROSSET, Clement. O real e seu duplo: ensaio sobre a ilusão. Tradução de José Thomas Brum. Rio de Janeiro: José Olympio, 2008.

SCHMIDT, Jochen. Reflection of the times. Theinter-and-multimidia of Tanztheather in Germany. In: TANZTHEATHER today. Thrirty years of german dance history. Hannover: Kallmeyersche, p.8-12, 1977.

THIOLLENTE, Michel. Metodologia da pesquisa-ação. São Paulo: Cortez, 2008.

\section{SITES ELETRÔNICOS CONSULTADOS}

LINKE, Susanne. Só movimentos necessários. Revista Época (Por Gisela Anauate). Lyon, 24/10/2008. p. 13-14. 
$<$ http://revistaepoca.globo.com/Revista/Epoca/0,,EMI15548-15220,00-

SUSANNE+LINKE+SO+MOVIMENTOS+NECESSARIOS.html> Atualizado em 29/10/2008.

PEREIRA, Sayonara. Susanne Linke e o legado do tanztheater. Conectedance. Brasil. 2009. Disponível em <http://www.conectedance.com.br/materia.php?id=78> . Acessado em: 04/03/2010.

SILVA, Eliana Rodrigues. Encenação e Cenografia para Dança 2. Diálogos Possíveis. FSBA, Jan./jun. 2007. Disponível em:

$<$ www.fsba.edu.br/dialogospossiveis $>$. Acessado em: 15/01/2011.

\section{VIDEOGRAFIA}

LINKE, Susanne. Markische Landschaft. Tanz im August, Hebbel Theater, 1994. 